\title{
The place for individual conscience
}

Frances Kissling Catholics For a Free Choice, Washington, DC, USA

\begin{abstract}
From a liberationist, feminist, and Catholic point of view, this article attempts to understand the decision of abortion. People are constantly testing their principles and values against the question of abortion. Advances in technology, the rise of communitarianism and the rejection of individualism, and the commodification of children are factors in the way in which the abortion debate is being constructed in society. The paper offers solutions to end the ugliness of the abortion debate by suggesting that we would be able to progress further on the issue of abortion if we looked for the good in the opposing viewpoint. The article continues with a discussion of Catholics For a Free Choice's position on abortion, and notes firstly that there is no firm position within the Catholic Church on when the fetus becomes a person; secondly that the principle of probablism in Roman Catholicism holds that where the church cannot speak definitively on a matter of fact (in this case, on the personhood of the fetus), the consciences of individual Catholics must be primary and respected, and thirdly that the absolute prohibition on abortion by the church is not infallible. In conclusion, only the woman herself can make the abortion decision.

(Fournal of Medical Ethics 2001;27 supp1 II:ii24-ii27)
\end{abstract}

Keywords: Catholic; conscience; feminist; fetus; abortion; technology

The question of a new ethic of abortion is one I will be approaching from a Catholic, feminist, liberationist perspective. Catholic, in the sense that my religious tradition is Roman Catholic and I am deeply dedicated to the social justice and intellectual tradition that is part of that faith. Feminist, in that what I ask myself when I look at a social problem is, what effect will a value or a policy have on women's wellbeing. Therefore, in the discourse on abortion I am more inclined to pay attention to what this says about women, although this does not mean that I ignore the fetus or think fetuses are without value. From a liberationist perspective I ask the same question: what effect does a principle, value or policy have on those among us who are poorest, marginalised, and most vulnerable. In the abortion debate in the developed world we have concentrated on the effect of technology, particularly medical technology. There are people in a whole part of the world, however, for whom these technological questions are totally meaningless. Instead the question is one of day-to-day survival, whether one can care for a family, and whether one can bring new children into the world and care for them well.
Is there a new ethic of abortion? Do we need a new ethic? Or are we experiencing new situations, new events and new circumstances that have arisen since the late sixties and early seventies when abortion became legal in many countries? These new situations have provided each of us with challenges from whatever perspective we approach the abortion question. They provide us with challenges to the basic values and principles that underlie our support or opposition to legal abortion and to the morality of abortion. In American and European society, much of what we see as new realities gets tested in the prism of abortion. Whether that is appropriate or inappropriate, that is what happens.

My perspective on the place of individual conscience in the abortion debate derives from my own Catholic, feminist, liberation principles. The principle of conscience certainly is Catholic, and it certainly is religious. Most faith groups that have a theologically centred reality include the central notion that an individual answers personally to God for what that individual has done. Since individuals answer for their behaviour, then those individuals must have the freedom to act on their deeply held, reflected beliefs. Conscience is not laissez-faire behaviour. It involves deep reflection on one's values, one's faith, and one's circumstances. The question of whether we bring new life into the world or whether we don't, of whether we have an abortion or whether we don't, is a moral question and one's conscience is the best guide for making such a decision.

There is more than one important value at stake in the abortion decision. We can look at abortion in a very negative way, regarding it as evil, for example, when people talk about the "lesser of the two evils". Or we can say that, when one faces a pregnancy in which there is a need to decide whether to continue with it or not, one is confronted with two or more important values. The value of life is there, which is a deep and important value for most people, and this includes the value of the fetus's life and the value of the woman's life. Physical life is not the only value. I come from a Christian tradition in which Jesus Christ died for the sins of all humanity, and God chose that his son's life was taken, so we do not have a system in which death is viewed as the worst thing that can happen. One can respect life but understand that life can be taken, and one can see values that are greater than or equal to the life of the fetus as being worthy of exploration by individual conscience.

When we talk about technology, the discourse continues to be focused on the fetus rather than on 
women. This is because technology to make women's lives better is not part of the medical or scientific agenda. However, I am very supportive of technology that relates to fetal life and newborn children's lives. One of the things that someone who respects individual conscience would say on this matter is that woman are competent, able, moral agents, but they have not always been recognised as such, and their competency is still questioned in some quarters. Therefore when it comes to something as profound as the abortion decision, it is critical that in a social and legal construct we look for policies that affirm the capacity of women to make complex moral decisions without intrusion by state or by faith. Advice gratefully accepted, dictates rejected. There are other ethical matters at play in the universe today besides principlism. For example, there is such a thing as feminist ethics. I was once scolded by the US feminist Christian ethicist Beverly Harrison for holding a conference on applied ethics. She reminded me that all ethics is applied and that ethical principles derive from experience, not from the abstract level. There needs to be an interplay between the abstract and objective sphere, and the experiential sphere. We hear very little about the experiential sphere when we talk about abortion and the derivation or the setting of moral principles and values.

I want to make a few remarks about some of the new circumstances and situations against which people now test their principles and values as related to the abortion question. One is the rise of the concept of fetal-maternal conflict. Twenty years ago we did not talk about fetuses and mothers being enemies or adversaries. We assumed a commonality of interests between mother and child, or mother and fetus. Now we live in a world in which we assume conflict between the pregnant woman and the fetus. Another element is the rise of concern over infertility, as opposed to the concerns about controlling fertility. When abortion became lega we were much more concerned about the ability to prevent pregnancy and have fewer children. Now we are much more worried as a society about whether women and couples who want babies are able to have them.

Included in this is the increasing commodification of children as products. It is a very important part of the identity of many people within Northern, Western societies to have the right kind of child, at the right time, with all the right characteristics, to prove that we are good people. This affects the way in which abortion is regarded. There are also technological advances in contraception as well as abortion. I would hope that in the future one of the things we will see is that, as abortion becomes more readily available, women will be able to seek and have abortions much earlier in pregnancy. We are also facing new challenges to contraception in that many consider some contraceptives to be abortifacients and this then becomes a dilemma. We may not have to worry about late abortions in the future, but we may need to worry about whether even early abortions will occur and whether new contraceptive methods will be accepted as contraception.

We are also facing the rise of the concept of communitarianism and the rejection of individualism, the rejection of rights even with the notion that rights theory is a conflictive model of human relationships and needs to be eradicated. This affects how the abortion issue and ethical arguments related to abortion are constructed. We face an enormous backlash against feminism and the achievements that feminism has made. That affects the way in which we talk about abortion and what we think about women's rights relative to abortion. In my most futuristic thinking I believe we face the question of the very definition of abortion. If we can produce children outside of a woman's uterus, what is the definition of abortion in those circumstances? Is the definition of abortion the removal of a fetus from an unwilling host? Or is the definition of abortion the death of the fetus? That becomes a critical question, and people will have to come to grips with their deepest ethical values.

Part of the new ethics of abortion is how the abortion debate is going to be conducted in society. People on all sides of this question have faced one of the most divisive, polarised, ugly, and sometimes violent debates. This ugliness, polarisation and certainly verbal violence, is something in which both those who support abortion and those who are opposed to abortion have participated. As a result, we have had a discourse on abortion that is really puny, in which most decent people, both pro-life and pro-choice, have been left behind and out of the discourse.

Those who are opposed to abortion talk to each other most of the time, those of us who are pro-choice talk to each other and not the "other" most of the time. If there were to be anything new in the ethics of abortion, I would say it should be an ethical commitment to rational, civil discourse and an openness to curiosity on the part of partisans on both sides of the question. None of us is curious enough about what someone who disagrees with us thinks on this issue. The majority of the time, when we listen to someone with whom we disagree, our mind is immediately constructing how to destroy the argument of the other. But the reality is that we are facing a highly complex issue. That does not mean one cannot have strongly held values which support one position or another. But there is good in the concerns, values, and principles of those who are opposed to abortion as well as in the concerns, values and principles of those who support abortion. We probably could get a lot further on this issue if we started to look for the good in the other's position rather than for the ways in which we can destroy that with which we disagree.

I would now like to describe Catholics for a Free Choice's (CFFC) position on abortion. Catholics for a Free Choice's position on abortion is appropriately complex; it is not easy to reduce it to a sound bite. Even the sound bite most often used by those who are opposed to legal abortion"abortion on demand"-is hard to understand. I 
think it is usually a pejorative meant to characterise those who favour legal abortion as extremists or "abortionists." In our minds, CFFC is not for "abortion on demand". We think abortion is a serious moral matter which requires reflection, including dialogue with partners and trusted advisors. It is not a casual event. We firmly believe that women are moral agents and as a matter of law should be allowed to make the decision whether or not to have an abortion with minimal state intervention. If this is how one defines "abortion on demand," then one would conclude we are for abortion on demand.

The corollary to this is the charge by those who are pro-choice that those who are opposed to legal abortion are "anti-woman". And indeed, I would say that those who are opposed to legal abortion do not fully recognise women as moral agents. But are we in the pro-choice community well served by reducing the abortion discussion to pejorative ways of defining others' positions?

Abortion is a complex moral matter. It cannot be reduced to either absolutism: "rights of the fetus" nor "rights of the woman". For CFFC, a central value in this complex matter is the recognition that women are competent, capable moral agents who must be recognised as having both the moral and the legal right to make the decision about whether or not abortion is justified in their specific circumstances. Some women will make decisions others evaluate as "good"; some women will make decisions others evaluate as "bad". No one, however, can make this decision for a woman.

In a Catholic theological context and in the realm of morality this respect for women as decision makers on the abortion question is based on a number of facts:

1. There is no firm position within the Catholic Church on when the fetus becomes a person. This can be confirmed by reading The History of Abortion in the Catholic Church: The Untold Story, a CFFC publication by Jane Hurst ${ }^{1}$; $A$ Brief, Liberal, Catholic Defense of Abortion by Daniel Dombrowski and Robert Deltete ${ }^{2}$; the Declaration on Procured Abortion, published by the Sacred Congregation for the Doctrine of the Faith (1974) and numerous other books, articles, etc. ${ }^{3}$ The preponderance of scientific, medical, sociological, and philosophical writing leans strongly to the position that fetuses do not possess the characteristics most commonly cited as markers for personhood. Women, however, are clearly persons, with the right to be treated as moral decisionmakers.

2. The principle of probablism in Roman Catholicism holds that where the church cannot speak definitively on a matter of fact (in this case, on the personhood of the fetus), the consciences of individual Catholics must be primary and respected. (See Catholic Options in the Abortion Debate, by Daniel Maguire, ${ }^{4}$ and "The tradition of probabilism and the moral status of the early embryo" by Carol Tauer, in Abortion and Catholicism, edited by Patricia Beattie Jung and Thomas Shannon. ${ }^{4}$ )
3. The absolute prohibition on abortion by the church is not infallible. Therefore we defend the right of Catholics to take positions on the morality and the legality of abortion which differ from that of the church. The latest proof that the position is not infallible is the fact that early drafts of the encyclical Evangelium Vitae did say it was an infallible position, while the final version excluded this claim. ${ }^{5}$

Within Catholics for a Free Choice, people hold different views on the morality of abortion. Some believe abortion can only be morally justified in a few circumstances: when the woman's life or health is in danger, or in cases of incest or rape, for example. Some believe it is justified in a wide range of circumstances. Some believe it is almost always justified and that a woman's right is near absolute. The organisational position is that none of these positions should be asserted dogmatically, nor should they be binding on the conscience of a pregnant woman. Each abortion decision stands on its own and must be evaluated in light of the woman's circumstances and conscience and in light of her belief about the issues. While there is no moral right to abortion, there is a moral right to make decisions, including the decision to have an abortion.

In the legal realm, CFFC favours laws on abortion that support the right of women to decide whether to have an abortion with minimal state involvement. Because we believe abortion is a moral matter on which people may legitimately hold differing views, we think it is the responsibility of the state to protect the right to choose, but not to make the decision for women. We are as opposed to forced abortions, such as those which take place in China, as we are to forced pregnancy as preached by the church.

There is no perfect law. Generally, we favour more liberal rather than more restrictive laws. We believe women can be trusted to make good decisions and do not need their pregnancies micromanaged by the state. In fact, we believe most states are profoundly unqualified to make this decision for women. The risk of coercion when the state is involved in reproduction is great. We do not think the state is competent to evaluate fairly the reasons a woman may give for an abortion, and, again, are prepared to leave the judgment about whether an abortion is right or wrong to the woman. We accept that some women may make bad decisions. We believe most women make good ones.

We have never opposed laws that limit abortion after viability, so long as abortion is available to save a woman's life and health. We have never opposed any of the moderately liberal and somewhat restrictive laws on abortion in Europe, even though we think they are too restrictive. As a practical matter, we are concerned with countries, particularly in the developing world, where abortion laws are so restrictive that women are dying as a result of illegal abortions.

We do not believe that women's moral agency requires that abortion be legal without regulation throughout the nine months of pregnancy. We 
understand the function of law as teacher. In this context, laws that respect women's moral agency, while expressing respect for the increasing value (not rights) of fetal life as a pregnancy advances, make sense. Thus, if abortion is legally available without restrictions in the early stages of pregnancy, and, in serious circumstances regarding the health or life of the woman, is available later in pregnancy, we believe that women's autonomy and moral agency are most likely adequately respected.

We also recognise that most of the world's religions have positions that respect the right of women to make this decision and believe that laws against abortion will violate generally accepted religious values and beliefs such as conscience.

We do not think abortion as such is a moral good, although, as I said above, it can be a morally correct decision. As reform Catholics, we are suspicious of the way in which language has been used to degrade and demean people in the church. We have always favoured the positive - for example, Matthew Fox's idea of "original blessing," as opposed to the institutional "original sin". ${ }^{6}$ We are careful to use the word "evil" very rarely, if at all. We'd probably use it only in relation to grave social injustices that are systemic, rather than in reference to individual moral actions. Therefore, we would never refer to abortion as "evil".

We do think abortion is to be avoided by engaging in responsible sexuality, including the use of contraception. However, once a woman is pregnant, the moral decision needs to be based on circumstances and moral beliefs-not prohibited or condemned because one was "irresponsible".

We think the question of abortion is surrounded by moral hypocrisy, not just on the part of the hierarchy, who hide the truth about Catholic theology and insights on this question, but on the part of most Catholics. Few believe in the absolute prohibition of all abortions. Most admit to some moral exceptions. Once one accepts that there can be exceptions, the question really becomes who will decide which exceptions are legitimate. Moreover, fewer still are willing to see laws against abortion that would actually be enforced. Would any of us say that women who have abortions should be tried and sentenced to prison as murderers? Do we see no moral distinction between abortion, especially early in pregnancy, and the murder of infants and children by their fathers and mothers? Can we hold such distinctions and still truly say we believe fetuses are people? I must confess that I do not understand those who are opposed to allowing women to make the decision about abortion and yet call themselves reform Catholics, saying they want to see women treated as equals in the church, and claiming to care deeply about eliminating poverty and marginalisation. I have a hard time respecting their views and their actions as justice-seeking.

I hope this begins to answer the questions regarding the position Catholics for a Free Choice takes on abortion. For further information, I would like to direct readers to our websitewww.catholicsforchoice.org - where we have many articles that address the issue of individual conscience, abortion, and the Catholic tradition.

\section{Acknowledgement}

Part of this article first appeared as Abortion: articulating a moral view, by Frances Kissling, in Conscience: A Newsjournal of Prochoice Catholic Opinion, 2000, volume XXI. Reprinted by permission.

Frances Kissling is the President of Catholics For a Free Choice, Washington, DC, USA.

\section{References}

1 Hurst J. The history of abortion in the Catholic church: the untold story. Washington DC: CFFC, 1989

2 Dombrowski D, Deltete R. A brief, liberal Catholic defense of abortion. Urbana and Chicago: University of Illinois Press, 2000.

3 Sacred Congregation for the Doctrine of Faith. Declaration on procured abortion. Rome: Sacred Congregation for the Doctrine of Faith, 1974.

4 Maguire D. Catholic options in the abortion debate. CFFC briefing for pro-choice legislators, March 1983. Tauer C. The tradition of probabilism and the moral status of the early embryo. In: Jung PB, Shannon T, eds. Abortion and Catholicism. New In: Jung PB, Shannon T, eds. Abortion and

5 Evangelium vitae. Issued by Pope John Paul II. Vatican City: Vatican Library, March 251995.

6 Fox M. Original blessing. Santa Fe, NM: Bear Publishers, 1983. 